\title{
Aboveground storage of hydrocarbon gas hydrates
}

\author{
Mykola Zotsenko ${ }^{1 *}$, Larysa Pedchenko ${ }^{1}$, and Andrii Manhura ${ }^{1}$ \\ ${ }^{1}$ Poltava National Technical Yuri Kondratyuk University, Department of Oil and Gas Exploitation \\ and Geotechnics, 24 Pershotravnevyi Ave., 36011 Poltava, Ukraine
}

\begin{abstract}
The work objective is to substantiate the technical bases for the production of gas hydrate blocks directly on-site for further transportation and storage in above ground storages, as an alternative to transporting and storing gas in underground gas storages. The theoretical bases have been considered and processes of gas hydrate blocks producing, physicalmechanical characteristics of artificial hydrates with the purpose of determining the conditions of their storage and prolonged storage were tested in laboratory conditions. The construction of above ground gas hydrate storage in the form of a building, partially deepened in a ground, which is separated from the environment by a wall of gravel cement elements made by the mixing method were substantiated. It is proved that such a constructive solution for a long-term storage of gas hydrate blocks is the most economical in terms of energy consumption to maintain internal negative temperature.
\end{abstract}

\section{Introduction}

Gas hydrates - solid combination of a cage type of variable class - clathrates. The clathrate compound is described by the formula $\mathrm{M} \cdot \mathrm{n} \cdot \mathrm{H}_{2} \mathrm{O}$, where $M$ is the molecule of the gas involved in hydrate formation; $n$ - the number of water molecules belonging to one included molecule of gas and depends on the type of gas, pressure and temperature [1 - 3]. Gas hydrates are formed by the inclusion of gas molecules in the cavity of the frame (crystalline lattice) and temperature, built up by $\mathrm{H}_{2} \mathrm{O}$ molecules under certain, for each component of gas, thermodynamic conditions [4]. With their violation gas molecules that were held in the lattice water skeleton by the weak forces of Van der Waals, leave it and hydrate is decomposed into gas and fresh water with a significant absorption of heat. The water molecules skeleton of methanhydrate is a cubic structure similar to ice and many properties similar to it. Its density varies within $0.908-0.917 \mathrm{~g} / \mathrm{cm}^{3}$ depending on the type of structure of the gas hydrate and the filling of its cavities $\mathrm{CH}_{4}$ [5]. Specific gas content $\mathrm{CH}_{4}$, at full filling of cavities of gas hydrates of the cubic structure of the I-th type with density $0.916 \mathrm{~g} / \mathrm{cm}^{3}$, when decomposition is $170.6 \mathrm{~m}^{3}$ [6].

The thermodynamic stability of gas hydrates is a basic condition for the medium of formation and preservation of hydrates and, accordingly, an important criterion for detecting zones of possible hydration formation (ZPHF). Violation of the thermodynamic

\footnotetext{
*Corresponding author: zotcenco@hotmail.com
} 
conditions in the system leads to the decomposition of hydrates.

The main parameters of the reservoir, which should be characterized in this case for the allocation of ZPHF, - temperature, pressure, composition of gas and mineralization of reservoir water, as well as lytofascial composition (permeability) of the reservoir [7]. High mineralization of reservoir water not only inhibits, but sometimes also eliminates the possibility of hydrotreatment processes [7], since the cavities of the lattice water skeleton are occupied by salt molecules. It is generally known that $\mathrm{CaCl}_{2}$ in concentration $25-35 \%$ (weight) is an active inhibitor of man-made gas hydrate formation and is widely used in oilfield practice to prevent it.

In the work of M. Pedchenko [8-10] the method of hydrate production of the accompanying petroleum gas for the purpose of its transportation and storage is offered (Fig. 1).

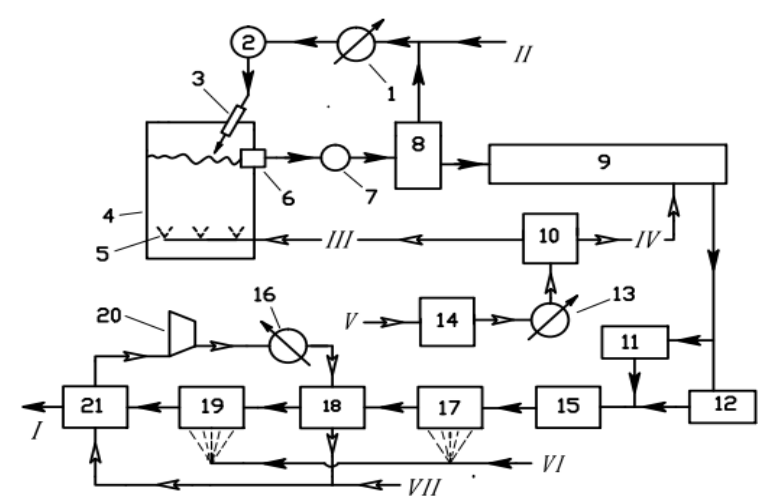

Fig. 1. Method of production of gas hydrate blocks: 1 - cooling of water; 2 - water pumping; 3 - feed water stream into the reactor; 4 - formation of gas hydrates; 5 - bubbling gas; 6 - selection of gas hydrates; 7 - vibration treatment; 8 - separation; 9 - concentration and cooling; 10 - crushing of hydrate; 11 - pelleting of hydrate; 12 - separation of gas; 13 - cooling of gas; 14 - preparation of gas; 15 - formation of blocks; 16 - cooling of air; 17 - the first water supply to the blocks; 19 - the second water supply on the blocks; 18 - cementing surface; 21 - freezing of the ice layer; 20 - air circulation; stream: I - blocks; II, VI - water; III - methane; IV - condensate; V - gas; VII - air.

The method involves the production of gas hydrates in the form of gas hydrate blocks and includes: preparation of gas and water; formation of gas hydrate; separation of the maximum amount of gas and water from the water - gas hydrate mixture, which was not included in the composition of the gas hydrate (separation); dehydration of a part of a film water (in order to concentrate the gas hydrate in the target product) by its binding in a gas hydrate at a contact with a part of a raw gas; freezing of gas hydrate; formation of a part of granules hydrate mass and crushing of another; formation of a gas hydrate block (GB) from a mixture of crushed and granulated gas hydrate; preserving of GB with ice crust (by double coating the surface of the water and freezing the flow of cooled gas at atmospheric pressure). As a way to increase the stability of the gas hydrate, it was chosen to preserve it with a layer of more stable gas hydrate. To do this, a layer of gas hydrate with the highest content of ethane, propane and $i$-butane is formed on the surface of hydrated mass particles. Gas enriched with ethane, propane and $i$-butane, has been previously obtained by fractionation of raw gas during its separation after compulsory cooling. Due to the temperature and pressure conditions of hydrate formation process in the reactor and in the process of drying gas components that were not included in the composition of the gas hydrate, but these conditions are captured in the form of droplets in the intercrystal space. Taking into account the insignificant specific content of such components in the gas 
entering the process, the presence of these inclusions does not affect the stability of the formed gas hydrate blocks. Experiments [8] show that these components are safely preserved in the volume of the gas hydrate mass, even after the pressure has been dropped to atmospheric.

In order to create optimal conditions for intensive hydration formation during the drainage process, namely prevention of water freezing, it is assumed in this work that the temperature of the water - gas hydrate mixture should be maintained at $275 \mathrm{~K}$. This is done by taking into account the balance of the enthalpy of gas streams of dehumidification and cooling of the gas hydrate mass entering the drainage, and the enthalpy of hydration formation. The optimum drainage parameters are maintained taking into account the humidity of the gas hydrate mass, the composition of the drying gas and the rate of hydration so that the maximum amount of water is bound to the gas hydrate even before the temperature drop is lower than $273 \mathrm{~K}$. Heat utilization of hydrate formation and cooling of the gas hydrate mass is carried out mainly by forced circulation of a portion of the drying gas through an external heat exchanger, which is not indicated in the diagram. The rate of hydration formation in contact with the gas with ice is insignificant in comparison with the process of interaction between gas and water [11]. Therefore, the gas flow, after cooling it to a temperature below $273 \mathrm{~K}$, initially cooled the gas hydrate mass, which was drained and preserved more stable gas hydrate. After heating to $273 \mathrm{~K}$, the gas during the dehumidification is actively included in the hydrate. Moreover, gas and gas hydrate in these successive processes move toward each other. In the device for carrying out the drainage process 9 between the zone of hydration and the cooling zone there is a zone of quality control of this process. Since the temperature of the gas hydrate mass is below $273 \mathrm{~K}$ it requires the maximum amount of water to be connected to the gas hydrate, then, accordingly, the humidity of the gas hydrate mass in the intermediate zone is an indicator of the quality of the drying process. In the above mentioned device for the formation of hydrate, gas is fed after separating it from the homologues of methane in the form of condensate (for use in the process of drying). Due to the change in the composition of the gas (the loss of parts of the heavier components), the thermobaric conditions in the reactor for the implementation of the process are supported more rigid than for the initial gas composition. To improve the quality of the formed mixture and the completion of the hydration process, it was suggested that the water - gas hydrate mixture withdrawn from the reactor should be subjected to vibration treatment for the destruction of the hydrated crust bubbles. The process of hydration heat removing from the reactor zone is carried out from the water - gas hydrate mixture outside the reactor. Moreover, heat removal, removal from the reactor of the formed hydrate and supply to the reactor of the required amount of water was combined into one process. The purpose of the operation for the formation of hydrate structures is the maximum reduction of porosity to increase the specific content of hydrate and mechanical strength, to prevent the heterogeneity of their structure, reduce energy consumption and the duration of the production cycle. The production of hydrate monolithic blocks includes the following steps: the separation of dried and frozen gas hydrate into two streams with a bulk ratio of the first and second 48 and 52\% respectively; grinding of the first stream hydrate; pressing of granules from hydrate of the second stream in the size of $20-30 \mathrm{~mm}$; uniform mixing of granular and crushed hydrate; pressing of formed mixture in the form of cylinders or hexagonal prisms of appropriate sizes; formation of ice blocks produced on the surface. Consequently, the gas hydrate structures [8] formed by the method are suitable for long-term storage and transportation under atmospheric pressure and a slight negative temperature. 


\section{Principles of artificial gas hydrate blocks formation for their transportation and storage}

Having analyzed the work [8 - 13], from the theoretical substantiation of the parameters of the process of intensive hydration formation, one can conclude that the process of gas hydrated blocks production, as well as granulated gas hydrate, consists of several technological operations. Among them, the most responsible is the formation of blocks. The paper [8] substantiates the necessity of conducting experiments for setting parameters, which describes the process of the gas hydrate mass compressing during the formation of gas hydrate blocks at a temperature not exceeding $263 \mathrm{~K}$. The aim of the work was to study the rheological properties of the gas hydrate mass and to check the adequacy of the proposed method and technology for the production of large-sized gas hydrate blocks with the aim of their transportation and long-term storage. The process of a gas hydrate mass formation is carried out by its compression. When applying force to the body on one axis, in the absence of lateral walls, there are transverse forces of stretching $F_{s t r}$. Between the faces of the cylindrical sample diameter $d$ and height $h$, and press plates they are balanced by friction force $F_{f r i c}$. By the length of the sample there is a place where the forces of stretching $F_{s t r}$ reach the highest value, and frictional forces $F_{\text {fric }}$ - the smallest $(h / 2)$. With an increase in height $h$ the forces of $F_{\text {str }}$ increase and $F_{\text {fric }}$ forces decrease. Hence, the compression strength of samples with proportions $d \approx h$ is considerably higher than the variant with parameters $d<h$.

In the case of the presence of vertical walls during compression of a gas hydrate mass of cylindrical shape, the transverse forces of stretching $F_{\text {str }}$ that occur in this case will be counterbalanced by the forces of the resistance of the lateral walls. As a result, the surface layer of the hydrate mass is better compressed than internal one (Fig. 2). That is, the formed gas hydrate block will have an inhomogeneous porosity.

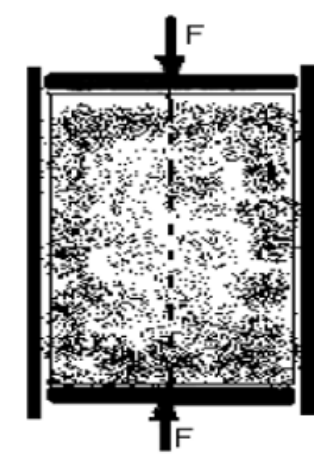

Fig. 2. Scheme of sample compression (heterogeneous porosity of gas hydrate mass after pressing).

Taking into account this and the need to create energy-efficient technology, it was proposed to form blocks of large sizes in the form of cubes from a mixture of crushed and granular gas hydrate of minimum porosity, taken in the appropriate proportion $[8,9]$. Such a design of gas hydrate structures, as the basis of the proposed gas hydrate technology, allows simultaneously to solve problems of their uniform porosity (homogeneity) and maximum possible dense stacking during transportation and storage. It has been proved that during the formation of the gas-hydrate mass deformation goes beyond the limits of elasticity, the volume of the sample decreases. External forces perform work aimed at breaking the bonds between the crystals, reducing the volume of pore space, and counteract 
the forces of cohesion (regelation) between crystals of gas hydrate and ice at negative temperatures. In cube, as resistance to external forces, internal stress arises. Its value depends not only on the size of the deformation of the body, but also on the speed with which the external force acts on the subject. When forming by stroke, the internal stress will not be sufficiently large in comparison with the stress that occurs during slow compression. The internal stress arising during compression is manifested in the form of internal friction and will be directed against the action of external forces - in the direction of reducing the impact on the sample. Part of the work at sample deformation is spent on its heating.

However, according to the proposed [8, 9] technology of production of gas hydrate blocks, at the exit of the installation, their temperature should not be higher than $258 \mathrm{~K}$. Taking into account the physical properties of the gas hydrate, it was concluded that the duration of the cooling process of the manufactured blocks and, as a consequence, the time of their location in a suitable installation can not meet the conditions of industrial production. Therefore, the gas hydrate mass is proposed to cool down to the time of formation in blocks. Moreover, the level of supercooling should take into account the thermal balance of the operation, the optimum temperature of storage of hydrate blocks under atmospheric pressure and possible losses of energy during transportation and storage.

As a result of gas hydrate sample deformation, its partial dissociation will occur, even under thermobaric conditions that are consistent with its stability. This process occurs at low and high temperatures. Dissociation is a violation of the integrity of the crystal lattice and microcracks. At a temperature higher than $273 \mathrm{~K}$, there is the formation of water, the growth of nuclei of hydrate formation. When the sample is compressed, water migrates to intercrystalline space and causes its rapid deformation [8].

Comparison of mechanical strength of methane hydrate and ice of similar porosity showed that the relative rate of deformation of ice is 4.5 times higher [15]. For the formation of methane hydrate at a temperature of $253 \mathrm{~K}$, it was noted that it is necessary to add 10 times more effort than the formation of ice granules [8, 16, 17]. At temperatures below $273 \mathrm{~K}$, methane hydrate is 20 times stronger than ice. In addition, the difference increases with a temperature decrease [8].

In the process of compression of the gas hydrate mass, in addition to dissociation, there were several processes. Under the influence of pressure due to the melting of crystals at the point of contact and subsequent freezing, the process of regelation is manifested. In the case of breaking of the structure of crystals, they are freezing or "sticking". Due to these processes, the cracks are "treated" over time and the mass that is shrinked becomes stronger. After a certain time (5 - 10 hours) strength and hardness of it increase nine fold [18].

It can be concluded that the process of compressing the sample of gas hydrate is accompanied by the following processes: the destruction of the crystalline lattice of gas hydrate and ice; the conversion of part of mechanical energy into heat; partial dissociation of gas hydrate with the evolution of gas and free water (including supercooled) and the absorption of energy, necessary for its dissociation; the formation of gas hydrate from water and gas with the release of hydrate formation energy; heat exchange between porous space and crystals. Moreover, these processes take place simultaneously and mainly in the places of structural units contact. The predominance of one or another process depends on the initial temperature of the sample and gas pressure in the pores. Therefore, at a temperature higher than the point of crystallization of water, and atmospheric pressure, the processes of dissociation and destruction of crystals will prevail. Accordingly, at low temperatures, the processes corresponding to recrystallization predominate: re-formation (but in another form and elsewhere) of the gas hydrate from the products of dissociation and the crystallization of supercooled water. 
Also, the compression of gas hydrate during its formation is accompanied by a sharply expressed creep process, which, based on the nature of the gas hydrate, consists of a series of successive phase transitions on the verge of structural units. These transitions are subjected to certain laws and can not pass immediately. Therefore, taking into account the features of this type of phase transitions will enable to further optimize the parameters of the technological process of formation of gas hydrate blocks.

In order to substantiate the parameters of gas hydrate blocks formation in [8], it was proposed to establish the features of the process of the gas hydrate mass compressing, which are based on the rheological model, characterizing its stress-deformed state. One of its components is the work of the internal forces of elasticity, which arise as a reaction to the attached external forces. It is determined by the selected or experimentally established rheological model, which characterizes the stress-deformed state of the gas hydrate mass as a shrinking object.

The gas hydrate mass compressing experiment, which consisted of a mixture of powdered and granular gas hydrate, was conducted in laboratory conditions in order to establish its rheological parameters. The object of study in [8] was also the parameters of deformation (shrinking) of the sample with a gradual increase in load and its dependence on porosity and initial temperature.

Also, in the considered work, the experimental procedure was developed. It was based on the variation of the parameter $h$ (deformation values) with step and constant values of the internal stress $\sigma^{*}$ as a one-factor experiment. For this purpose, after each application of the force to the sample for one minute, the magnitude of its shrinkage was measured.

According to the results of the laboratory experiment, the regression equation (power function) was determined for the mathematical description of the dependence of the gas hydrate sample shrinkage on the magnitude of the created step load:

$$
P=0.103 \cdot h^{1.3},
$$

where $P$ - pressure on the sample, MPa; $a=0.103$ and $b=1.3$ - empirical coefficients; $h$-shrinkage of the gas hydrate block (investigated factor), $\mathrm{mm}$. Consequently, the shrinkage of the gas hydrate block increases with increasing compressing force (load) (correlation coefficients $r=0.99$ and variation $v=0.035$ ).

As a result of uniaxial compression, the length of gas hydrate samples decreased by $21.3-$ $21.6 \mathrm{~mm}$, while the average porosity of the block was within $0.06-0.08$. Obtained as a result of forming cylindrical forms of gas hydrate $(d=81 \mathrm{~mm}, h=102.6 \mathrm{~mm})$ had a uniform distribution of sample granules in a volume without the manifestations of their destruction or deformation. On the basis of the obtained results of measurements of samples shrinkage $h$ for each case of applying constant load $\sigma_{i}^{*}\left(\sigma_{i}^{*}=\right.$ const) a rheological diagram was depicted in Fig. 3.

These experimental research shows that for every such case when $\left(\sigma_{0}=\right.$ const) relative deformation varies slightly (within $0.0108 \leq \varepsilon_{0} \leq 0.0121$ ). By way of regression analysis of the OA section data (Fig. 3) it is established that the stress dependence $\sigma_{0}$ from the instantaneous deformation $\varepsilon_{0}$ is linear and described in the same way as Hooke's law:

$$
\sigma_{0}=E_{0} \varepsilon_{0}
$$

where $\sigma_{0}$ - internal stress, $\mathrm{Pa} ; E_{0}$ - instantaneous deformation module, $\mathrm{Pa} ; \varepsilon_{0}$ - instante deformation.

Experimentally obtained value of the instantaneous deformation module of the gas hydrate mass $E_{0}$ is given in Table 1 . 
Table 1. Rheological parameters of the gas hydrate mass, which are determined experimentally.

\begin{tabular}{|c|c|c|}
\hline Instantaneous deformation & \multicolumn{2}{|c|}{ Deformation of creep } \\
\hline $\begin{array}{c}\text { Instantaneous deformation module } \\
E_{0}, \mathrm{MPa}\end{array}$ & $\begin{array}{c}\text { Module of long } \\
\text { deformation } E_{l}, \mathrm{MPa}\end{array}$ & $\begin{array}{c}\text { Coefficient of viscosity } \eta, \\
\mathrm{MPa} \cdot \mathrm{s}\end{array}$ \\
\hline $26-369$ & $134-674$ & $1781-8905$ \\
\hline
\end{tabular}

Analysis of creep deformation change with time for $\sigma_{i}^{*}=$ const is carried out on the basis of $\mathrm{AB}$ senousction data (Fig. 3). At constant stress of the sample there was a dampening with time - creep.

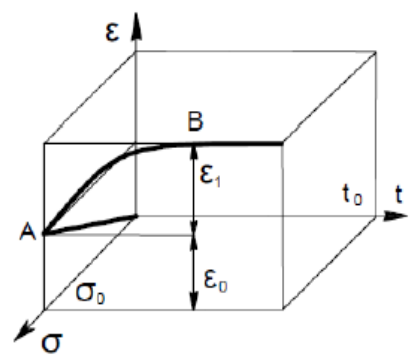

Fig. 3. Rheological model of gas hydrate compression at constant loading $\left(\sigma_{i}^{*}=\right.$ const $)$.

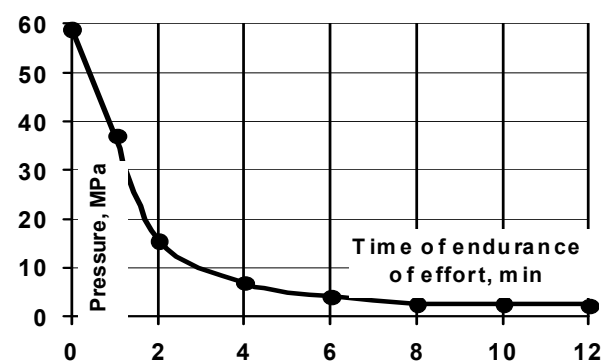

Fig. 4. Dependence of the pressure required to form a gas hydrate sample on the holding time.

The approximated exponential dependence (with coefficients of correlation $r=0.973$ and variation $v=0.045$ ), the change in the relative creep deformation of gas hydrate sample with time, according to experimental data, has the form:

$$
\varepsilon_{1}=0.0089\left(1-e^{-0,076 \tau}\right),
$$

where $A^{\prime}=0.0089$ and $B^{\prime}=-0.076$ - empirical coefficients; $\varepsilon_{1}$ - relative deformation of creep; $\tau$ - time, s.

On the basis of experimental data processing it was established that the deformation change with time is described by the model of the elasto-viscous Kelvin-Voigt body (parallel connection of elastic and viscous elements) [19]:

$$
\sigma^{*}=\varepsilon_{1} E_{1}+\eta \frac{d \varepsilon_{1}}{d \tau}
$$

where $E_{1}$ - long-term deformation module, $\mathrm{Pa} ; \eta$ - coefficient of viscosity, Pa.s.

Using a rheological compressing model for a gas hydrate mass was calculated the following: a long-term deformation module $E_{1}$ and coefficient of viscosity $\eta$ (Table 1).

With the help of the established deformation model of the elastic-viscous body, the pressure required to form the hydrate blocks of the required porosity was calculated and the time for this process to be performed was determined. On the basis of the obtained data, a graph of the pressure dependence created per unit area was constructed from the time of the application of the force (Fig. 4).

As can be seen from the graph (Fig. 4), the pressure required to compress the sample of the gas hydrate to the installed porosity $(0.08-0.1)$, with the extension of time of the force bearing is sharply reduced. The duration of forming within the range of 7-9 $\mathrm{min}$ is optimal. Comparing with the short-term process (stroke), holding for 8 min reduces the 
pressure of the formation of the gas hydrate. Consequently, the process of creep is in a series of successive phase transitions on the verge of structural units. The process is subjected to certain laws and can not pass instantly. Therefore, taking into account the features of this type of phase transitions will enable to further optimize the parameters of the technological process of gas hydrate blocks formation.

\section{Methodical peculiarities of designing and construction of aboveground storage of hydrocarbon gas hydrates}

The next stage of the implementation of the new method of methane gases transporting and storing in the gas hydrate state is the production of an industrial design for the manufacture of gas hydrate blocks based on technology, the basis of which was set forth above. In our view, the production model of such a device should be placed on a mobile chassis in order to carry out work on the manufacture of gas hydrate blocks directly at facilities for the complex preparation of gas exploitation wells of oil and gas fields.

For convenient storage, gas hydrate blocks have to be manufactured in the form of cubes, with a side of $0.6 \mathrm{~m}$. As we know from the properties of gas hydrates in $1 \mathrm{~m}^{3}$ of methane hydrate at a pressure of $2.6 \mathrm{MPa}$ and a temperature of $273 \mathrm{~K}$, will contain $164 \mathrm{~m}^{3}$ of gas. The volume of gas that will be emitted due to the dissociation of the cubic gas hydrate block, with a side of $0.6 \mathrm{~m}$ and a volume of $0.216 \mathrm{~m}^{3}$, will be $35.5 \mathrm{~m}^{3}$. According to statistics, in $2017160 \mathrm{mln} \mathrm{m}^{3}$ of gas was spent for the needs of the industry in Poltava, which is $3.1 \mathrm{mln}$ for the week. It is proposed to create a aboveground storage facility for gas volume of $3.5 \cdot 10^{6} \mathrm{~m}^{3}$, capable of meeting the necessary industrial needs. The number of gas hydrate blocks, after which the dissociation will receive a weekly gas volume, will amount that is 100000 units. For reasons of the need to keep a certain temperature in the storage, it must be deepen in the ground as shown in Fig. 5a.

$a$

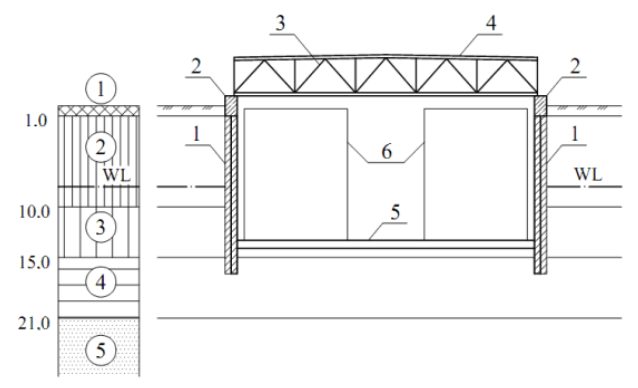

$b$

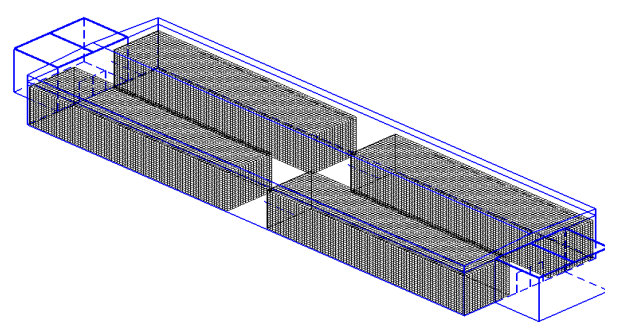

Fig. 5. Section (a) and general view in isometry (b) ground gas storage in hydrate state: 1 - walls from gravel cement elements; 2 - reinforced concrete belt; 3 - steel truss; 4 - thermally insulated coating; 5 - concrete floor; 6 - shelving of hydrate block.

Since the entrance to the cooling room externally involves a wind-poch, therefore, in addition to the storage of gas hydrate blocks, there are two transfer chambers: loading and unloading. Transfer chambers are transitional premises in which the loading of gas hydrate blocks is carried out for further transportation to the storage facility and, accordingly, their unloading, for subsequent delivery to the dissociation site. For greater convenience, loading and unloading works are carried out using gantry cranes located above the transfer chambers. The loading and unloading of gas hydrate blocks takes place through the sliding roof of the entrance and exit chambers. Sliding roof consists of two sliding elements, which for different tasks open independently of each other. The contour of the storage room 
consists of gravel cement elements, which are made from the surface of the Earth by mixing method to the excavation of the foundation pit. After the soil cement hardened, the inner volume of the soil is removed. Facing material for interior walls of the storage facility is plaster, with the addition of hydrophobic substances, with a thickness of $0.02 \mathrm{~m}$.

The walls between the storage room of gas hydrate blocks and gateways are made of bricks. Brick walls are designed from clay ordinary solid bricks, plastic molding of the brand is not lower than M100. The brick for the walls of the refrigerator buildings should have a mark of frost not lower than M25. Facing material for brick walls is also used plaster $0.02 \mathrm{~m}$ thick.

The cover of the storage is a construction made of metal trusses with a span of $30 \mathrm{~m}$, which is needed for the complete coverage of the storage. This construction is mounted on a reinforced concrete plinth. The base is arranged around the perimeter of the storage, $1 \mathrm{~m}$ high, and $1.2 \mathrm{~m}$ wide.

In determining the size of the ground storage of methane gas in the hydrated state, the volume of gas hydrate blocks that will be stored in it are taken into account. To this volume space for loading and unloading is added. And, finally, the volume of transfer chambers for receiving and sending hydrated blocks is added too. That is, the total volume of the storage will be $43907 \mathrm{~m}^{3}$, in this volume it is possible to place four assemblages of blocks of $45 \times 10.12 \times 12=5508 \mathrm{~m}^{3}$. After specifying the size of the storage, hydrate blocks in it

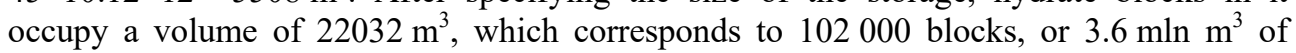
hydrocarbon gas. The general view of the storage with hydrate blocks in isometry is shown in Fig. 5b. For loading and unloading works in the storage, the telescopic loader of the British company - JCB model 535-125 - was chosen as the most rational one. It is characterized by a low center of gravity and a large outflow of the loader arm at its reduced cross-section, it is designed to work with massive loads at a height. Additional benefits of the JCB 535 - 125 include the steering, which has three modes of operation to control all four wheels, reduced by $250 \mathrm{~mm}$ radius of rotation, high maneuverability and geometric patency.

To prevent the spreading of structured water on the floor, it is assumed to be installed along the perimeter of the gutter system for drainage of water. The water through the trenches will flow to the drainage basins located in the corners of the storage and in each of the gateways. From the collectors, structured water is pumped off to the surface.

In the refrigerated facility, alarm systems should be provided: safety, fire, security and alarm systems for inadmissible level of gas contamination of premises. Emergency ventilation should have triggers both in and out of the ventilated areas, as well as automatically when the concentration of gas in the air above the maximum permissible level is increased. In all cases, the signal is provided in a room with 24-hour staffing.

Since the storage of gas hydrates is a structure in which there is a methane hydrate, it is necessary to install a supply and exhaust ventilation system. The sypply system supplies fresh air to the storage, and the exhaust system removes gaseous air from the room. By way of inducing air, the ventilation system refers to a system with mechanical induction (with the use of ventilating fans, ejectors, etc.). The connecting link between the storage of gas hydrate blocks and the entrance and exit transfer chambers is the sealed gates, which are additionally covered with thermal-insulating material.

The storage facility for gas hydrate blocks is a building with negative temperatures in the premises, which is not erected in permafrost soils, therefore, it is necessary to design a storage facility, taking into account the prevention of freezing of soils, which are the basis for foundations and floors. For this purpose, it is proposed to use artificial heating systems such as non-freezing liquids and electric heating. Soil protection systems for freezing should be provided under all rooms with negative temperatures, such as: storage and transfer chambers. 
Cooling of the storage room to a temperature of 253 - $268 \mathrm{~K}$ should be carried out using bivalent absorption heat pumps with a low-temperature source of energy - soil heat, as it provides a relatively uniform heat source temperature and high efficiency of the heat pump. Installation of heat exchangers of selected heat pumps is envisaged at the stage of creation of soil-cement elements of the second row of the enclosing structure of the storage facility.

According to preliminary data, the estimated cost of the proposed construction of a land storage of hydrocarbon gases in a hydrated state of 3.5 million $\mathrm{m}^{3}$ is about $65 \mathrm{mln}$ UAH. Taking into account that the lifetime of the storage building is 100 years, according to preliminary calculations, the estimated cost of manufacturing gas hydrates, storage and subsequent dissociation of natural gas in a hydrate state during the month is 223 UAH per $1000 \mathrm{~m}^{3}$ of free gas.

\section{Conclusions}

As a result of theoretical and experimental researches, the bases of creation of gas hydrate blocks from hydrocarbon gases by the transformation of gas into a hydrated mass under certain thermobaric conditions, densification of hydrate mass by a press to the given values of density and its shape, with subsequent preservation of a block by a layer of ice were developed. Thus, the conditions for the transportation and storage of hydrocarbon gas at atmospheric pressure and the negative temperature $253-26 \mathrm{~K}$ are created.

As an alternative to underground gas storage facilities, a $3.5 \mathrm{mln} \mathrm{m}^{3}$ of aboveground storage facility is proposed. The dimensions of the storage are $123 \times 31 \times 16$, the internal space is $43907 \mathrm{~m}^{3}$. The storage is deepened in the soil by placing its exterior walls without a preliminary excavation by means of their erosion from the surface of the Earth by the mixing method from the gravel cement elements. After hardening of the soil cement, the storage volume is released from the soil, insulating and finishing works are performed, the premises are covered and the necessary equipment is installed. Heat pumps are used in the storage to create a negative temperature. Estimated cost of construction is $65 \mathrm{mln}$ UAH. According to preliminary calculations, the estimated cost of manufacturing gas hydrates, storage and subsequent dissociation of natural gas in a hydrate state during the month is $223 \mathrm{UAH}$ per $1000 \mathrm{~m}^{3}$ of free gas.

This work has become possible due to financial and organizational support within the frames of the state budget research project under the auspices of the Ministry of Education and Science of Ukraine "Application of gas hydrate technology in the development of traditional and gas hydrate gas deposits" (State registration No. 0113U00857), "Research of influence of thermodynamic parameters of phase transitions in systems with gas hydrates on the efficiency of gas hydrate technology" (State registration No. 0115U002420). The authors express their gratitude to the supervisor of these projects - Doctor of Sciences, Professor, Head of the Underground Mining Department at the National Mining University (Dnipro) Volodymyr Bondarenko for his support in conducting the research.

\section{References}

1. Carrol John (2009). Natural Gas Hydrates. A Guide for Engineers, $2^{\text {nd }}$ Ed. Oxford: Gulf Professional Publishing.

2. Makogon, Yu.F. (2001). Prirodne gidraty: otkrytie i perspektivy. Gazovaya promyshlennost', (5), 10-16.

3. Makogon, Yu.F. (2010). Gazogidraty. Istoriya izycheniya i perspektivy osvoeniya. Geologiya $i$ poleznye iskopaemye mirovogo okeana, (2), 5-20.

4. Melnikov, V., \& Gennadinik, V. (2018). Cryodiversity: the world of cold on the Earth and in the 
solar system. Philosophy and Cosmology, (20), 43-54. https://doi.org/10.29202/phil-cosm/20/4

5. Levik, O.I. (2000). Thermophysical and Compositional Properties of Natural Gas Hydrate. Trondheim: Norwegian University of Science and Technology, Department of Petroleum Engineering and Applied Geophysics.

6. Dawe, R., Thomas, M., \& Kromah, M. (2003). Hydrate Techology for Transporting Natural Gas. Engineering Journal of the University of Qatar, (16), 11-18.

7. Musayev, R.M. (1977). Izuchenie izmeneniya entalpii sistemy "gaz - voda" pri obrazovanii odnoy tverdoy fazy gidratov. Trudy Vsesoyuznogo nauchno-issledovatel'skogo proektnogo instituta po podgotovke k transportirovke i pererabotke prirodnogo gaza, (4), 42-48.

8. Pedchenko, L.A., \& Pedchenko, M.M. (2013). Research of reology properties of gas hydration mass in the process it of forming. In Conference reports materials: Problems of energy saving and nature use 2013 (pp. 127-134). Budapest.

9. Pedchenko, L., \& Pedchenko, M. (2012). Substantiation of Method of Formation of Ice Hydrate Blocks with the Purpose of Transporting and Storage of Hydrate Gas. Naukovyi Visnyk Natsionalnoho Hirnychoho Universytetu, (1), 28-34.

10. Pedchenko, L.O., \& Pedchenko, M.M. (2013). The method production of hydrates of associated petroleum gas the purpose of their transportation and storage. Patent No. 101882, Ukraine.

11. Bondarenko, V., Kovalevska, I., Astafiev, D., \& Malova, O. (2018). Examination of Phase Transition of Mine Methane to Gas Hydrates and their Sudden Failure - Percy Bridgman's Effect. Solid State Phenomena, (277), 137-146. https://doi.org/10.4028/www.scientific.net/SSP.277.137

12. Lyubchak, O., Kolodiy, I., \& Khokha, Y. (2017). Thermobaric conditions of oil and gas contents and predicting of hydrocarbon phase state (on the example of the bilche-volytsa oil-and gasbearing area. Visnyk of V.N Karazin Kharkiv national university-series geology geography ecology, (46), 15-22. https://doi.org/10.26565/2410-7360-2017-46-02

13. Bondarenko, V., Svietkina, O., \& Sai, K. (2017). Study of the formation mechanism of gas hydrates of methane in the presence of surface-active substances. Eastern-European Journal of Enterprise Technologies, 5(6 (89)), 48-55. https://doi.org/10.15587/1729-4061.2017.112313

14. Yakushev, V., Gerasimov, Yu., Kvon, V., \& Istomin, V. (2008). The Current State of the Gas Hydrate Technology. Rewiew. Inf. OOO "Gazprom RPI".

15. Laura A. Stern, Stephen H. Kirby, \& William B. Durham. (1996). Peculiarities of Methane Clathrate Hydrate Formation and Solid-State Deformation, Including Possible Superheating of Water Ice. Science, 273(5283), 1843-1848. https://doi.org/10.1126/science.273.5283.1843

16. Durham, W.B., Kirby, S.H., Stern, L.A., \& Zhang, W. (2003). The strength and rheology of methane clathrate hydrate. Journal of Geophysical Research, 108(B4), 2-11. https://doi.org/10.1029/2002JB001872

17. Bondarenko, V., Lozynskyi, V., Sai, K., \& Anikushyna, K. (2015). An overview and prospectives of practical application of the biomass gasification technology in Ukraine. New Developments in Mining Engineering 2015: Theoretical and Practical Solutions of Mineral Resources Mining, 27-32. https://doi.org/10.1201/b19901-6

18. Tushinskiy, G.K. (1971). Inzhenernaya glatsiologiya. Moskva: Moskovskiy gosudarsnvennyy universitet.

19. Zotsenko, M.L., Kovalenko, V.I., Yakovlev, A.V., Petrakov, O.O., Shvec, V.B., Shcola, O.V., Bida, S.V., \& Vinnikov, Yu.L. (2004). Inzhenerna heolohiia: Mekhanika hruntiv, osnovy ta fundamenty. Poltava: Poltavskyi natsionalnyi technichnyi universytet. 